\title{
Subject-model sexual status and observer performance'
}

\author{
HENRY C. RICKARD AND CHARLES E. JOUBERT
}

UNIVERSITY OF ALABAMA

Four groups of 10 Ss each were instructed to say words intermittently with the taped voice of a male or female model (M). Ten male and 10 female Ss were exposed to each $M$. All four groups showed significant increases in the critical response class, animal words, as the frequency of animal words spoken by the taped $M s$ increased. There were no significant effects due to the sex of the Ss or sex of the $M$; a reliable interaction between the two variables was found.

Bandura \& Walters (1963) have hypothesized that an observer who perceives himself as similar to a model (M) is more likely to match the behavior of that M. A number of studies have found this predicted relation (Burnstein, Stotland, \& Zander, 1961; Rickard \& Lattal, 1967; Stotland, Zander, \& Natsoulas, 1961). The concept of subject-model similarity, however, is a very complex one. Similarity may be experimentally manipulated along numerous dimensions including intelligence (Rickard \& Lattal, 1967), status (Bandura \& Walters, 1963), and "competence" (Horwitz, 1966).

One obvious dimension of similarity occurs when both $M$ and $S$ belong to the same sex. An interesting question arises as to the importance of the similarity dimension among college students who are notoriously alert to members of the opposite sex. Which is the more influential in provoking imitative behavior, the male $M$ or the female $M$ ? Or is there an interaction effect indicating that $S$ sespond more strongly to members of the opposite sex?

Subjects

Twenty female Ss and 20 male Ss from introductory psychology classes served as Ss. Seven other Ss were excluded from the experiment for fallure to follow instructions or because of apparatus failure.

Apparatus

The Ss were seated about 20 in. from one wall of a $5 \mathrm{ft} \times 5 \mathrm{ft}$ cubicle painted flat black. A small signal light was mounted in the center of the wall opposite $S$ and a microphone was mounted 2 in. below the signal light. The $S$ wore earphones which were a part of an intercommunication system with an adjacent room from which E monitored and recorded S's responses. The $E$ used a toggle switch to activate the signal light on S's panel. Rather than using actual Ms, stimulus tapes were prepared with the voice of a 24-year-old female and a 28-year-old male. Each taped list was identical and consisted of 250 words. The first 50 words contained no names of animals, the critical response class. The next 50 words contained 9 , the next 50 contained 21 , the next 50 contrined 33 , the next 50 contained 45 , and the last 50 words were uniformly names of animals.
It was anticlpated that $S$ would tend to match the behavior of $M$ by emitting an increasing frequency of animal words across successive blocks of trials. The experimental design was a 2 by 2 factorial combining the sexual status of the $S$ with that of the model. Ten Ss were used in each of the four groups.

\section{Procedure}

The procedure was modified from an experiment reported by Kanfer \& Marston (1963). A large "Experiment in Progress" sign was placed on the door of E's room by which S had to pass to enter the experimental cubicle. The $S$ was seated in the experimental cubicle and asked to wait a few minutes until the $S$ in the next room had been instructed. The $E$ left the $S$ and returned a few minutes later to read the following basic instructions. "This is a study to see how different people use words. I am asking you to wear earphones so that you may hear some of what is said in the next room. When it is your turn, your light will blink. This is your signal to say a word. Say the first word you think of. Just one word. Do you have any questions?"'

The $E$ then entered the adjacent room and activated the tape recorder. At the end of the fifth taped word the tape recorder was stopped, $\mathrm{S}$ was signaled to respond, and the response was recorded by $\mathrm{E}$. This sequence continued until $\mathrm{S}$ made 50 responses.

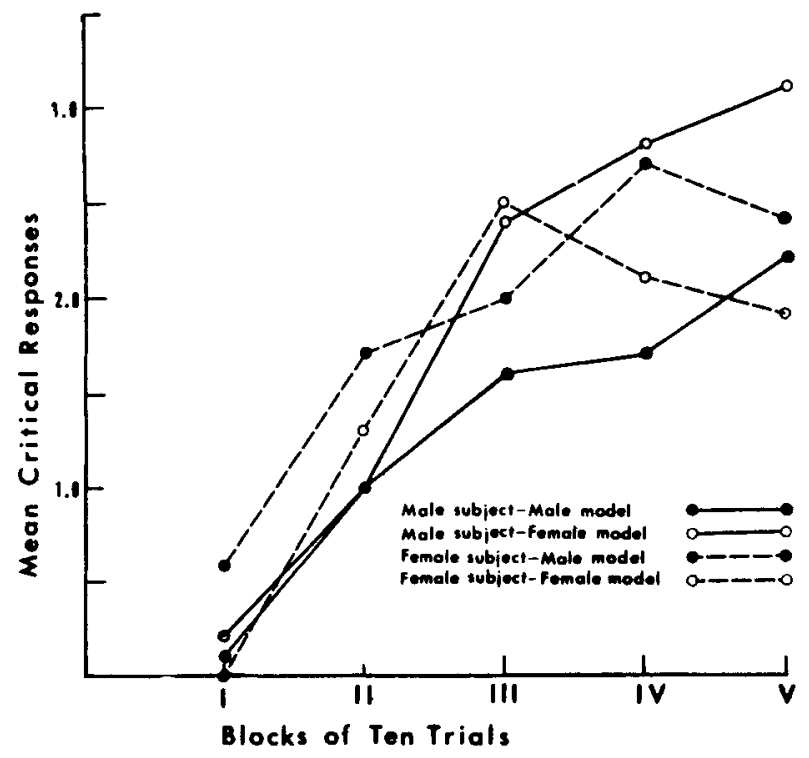

Fig. 1. Frequencies of critical responses for the four groups. 


\section{Results and Discussion}

The frequency of matching responses was analyzed in blocks of 10 trials. The curves for the four groups are presented in Fig. 1. In the first block of 10 trials animal responses constituted about $2 \%$ of the total words emitted by Ss; there were no significant differences among the groups in terms of frequency of animal responses. An analysis of variance performed on the last 10 trials for the four treatment groups revealed neither a significant sex of subject effect $(F=0.08, \mathrm{df}=1 / 36, \mathrm{p}>.20)$ nor a significant sex of model effect $(F=0.5, d f=1 / 36, p>.20)$. The interaction between sex of $M$ and sex of $S$ was significant, however $(F=5.11, d f=1 / 36, p<.05)$. Male Ss respond more strongly to the female $M$ and female $S s$ to the male M. Apparently, in the present experiment, sexual similarity was placed in direct competition with another subject-model variable, heterosexual attraction. Under the present conditions, the latter prevails.

\section{References}

BANDURA, A., \& WALTERS, R. H. Social learning and personality development. New York: Holt, Rinehart and Winston, 1963.

BURNSTEIN, E., STOTLAND, E., \& ZUNDER, A. Similarity to a model and self-evaluation. J. abnorm. soc. Psychol., 1961, 62, 257-264.

HORWITZ, $H$. The relationship of confidence to competence and imitation behavior. J. Psychol, 1966, 63, 235-247.

KANFER, F. J., \& MARSTON, A. R. Human reinforcement: Vicarious and direct. J. exp. Psychol., 1963, 65, 292-296.

RICKARD, H. C., \& LATTAL, K. A. Model similarity and observer learning. Psychol. Rep., 1967, 21, 501-506.

STOTLAND, E., ZUNDER, A., \& NATSOULAS, T. Generalization of interpersonal similarity. J. abnorm. soc. Psychol., 1961, 250-256.

Note

1. The authors wish to thank P. S. Siegel for his helpful comments. 